\title{
ЗОНДОВЫЕ ИЗМЕРЕНИЯ
}

\section{ПАРАМЕТРОВ ПОЛУПРОВОДНИКОВ: КОМПЛЕКСНЫЕ РЕШЕНИЯ}

\section{И.Васильев ${ }^{1}$}

УДК 621.317

BAK 05.11 .00

\author{
При изготовлении полупроводниковых приборов необходимо \\ контролировать их характеристики на всех этапах производства. \\ Один из видов контроля - зондовые измерения - позволяет \\ оценить качество исходной пластины, провести межоперационный \\ контроль, параметрический и функциональный анализ созданного \\ изделия. Кроме того, измерения на пластине проводятся для \\ верификации основных параметров разрабатываемых устройств \\ перед корпусированием в целях разбраковки и сортировки \\ по параметрам. Благодаря этому удается избежать дополнительных \\ затрат и снизить себестоимость продукции. Об особенностях \\ выполнения зондовых измерений и соответствующем \\ оборудовании рассказывается в статье.
}

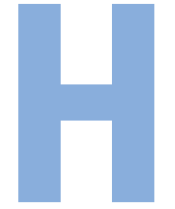

а первом этапе испытаний полупроводниковых приборов выполняются параметрические измерения по постоянному либо низкочастотному сигналу без проверки функционала устройства. В этом случае на вход устройства подается сигнал и регистрируется отклик на выходе. Как правило, параметрический контроль включает в себя измерение вольт-амперной (BAX) и вольт-фарадной (ВФХ) характеристик, а также импульсные измерения. После выполнения параметрических измерений появляется возможность составить карту пластины и определить долю бракованных устройств. Исходя из полученных данных и процентного соотношения выхода годных кристаллов на пла-

* ООО "Остек-Электро", ведущий инженер, vasilyev. @ostec-group.ru. стине оцениваются качество и эффективность процесса изготовления кристаллов. Высокая доля бракованных структур свидетельствует о наличии проблем в технологическом процессе.

На следующем этапе тестирования реализуется полный набор методик измерения и контроля характеристик исследуемого устройства (ИУ), в результате чего возможно построить модель для описания ИУ. Данная модель, включающая функциональные особенности прибора, позволяет дорабатывать его характеристики посредством компьютерного моделирования, не привязываясь к технологическому процессу.

Несмотря на то, что кристаллы, расположенные на одной подложке, проходят единый технологический процесс, всегда сохраняется некоторый разброс параметров устройств. С помощью зондовых измерений 
можно сортировать изготовленные устройства по категориям в зависимости от отклонения конкретного параметра от требуемой величины. Сортировка приборов гарантирует заданный уровень точности параметров выпускаемых изделий. Как правило, помимо самих устройств, на пластине также размещаются специальные тестовые структуры, которые помогают определить свойства определенного функционального слоя или качество выполнения конкретной технологической операции.

Для проведения описанных измерений необходима зондовая станция (рис.1), которая позволит соединить исследуемый прибор с измерительным устройством и обеспечит целостность и достоверность полученных результатов. По мере увеличения рабочих частот и уменьшения размеров разрабатываемых устройств приходится учитывать некоторые особенности измерений на пластине. Для получения достоверных результатов в первую очередь нужно уделять большое внимание характеристикам СВЧ зондовых головок, а также корректному проведению процедуры калибровки. Основные требования к параметрам СВЧ зондовой головки:

- небольшие размеры наконечника для уменьшения негативного воздействия на ИУ (снижения паразитной емкости между ИУ и измерительной головкой);

- постоянное сопротивление на всем протяжении зондовой головки (обеспечивает низкий КСВН);

- малые потери СвЧ-сигнала;

- полоса пропускания, достаточная для тестирования параметров ИУ;

- простота подключения к контрольно-измерительному оборудованию.

Другая важная задача -устранение влияния паразитного сопротивления кабелей, зондовых головок и контакта с ИУ при измерении. Для получения достоверных результатов необходимо выполнить калибровку по методикам TRL (thru-reflect-line), SOLT (short-open-line-thru)

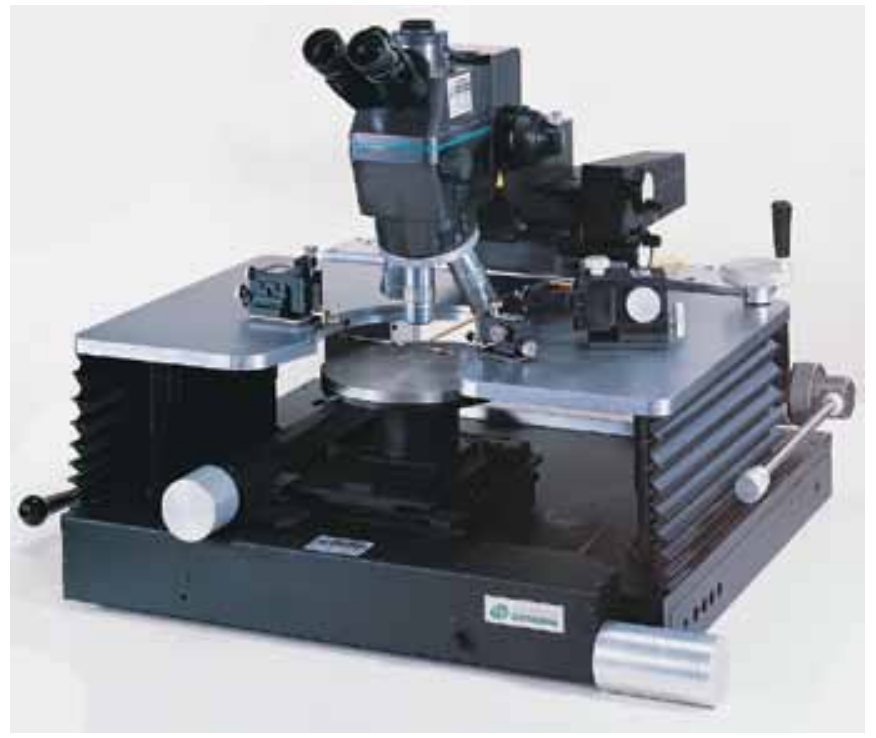

Рис.1. Ручная зондовая станция BD-8 компании EverBeing с возможностью измерений на постоянном токе и СВЧ

или LRM (line-reflect-match) на специальной калибровочной пластине, которая может различаться в зависимости от типа исследуемых устройств и способа контактирования. Однако даже очень точная калибровка может содержать ошибку. Это обусловлено изменением распределения электромагнитного поля в окрестности зонда при переходе от калибровочной пластины к ИУ, которое возникает из-за различия токопроводящих и диэлектрических свойств среды окружения зонда. Поэтому калибровочная пластина должна максимально повторять свойства исследуемой структуры. Кроме того, время между калибровкой и проведением измерений не должно быть слишком большим для устранения дрейфа параметров измерительной системы.

Еще один момент, который не следует упускать из виду, - повторяемость и качество контакта. Если
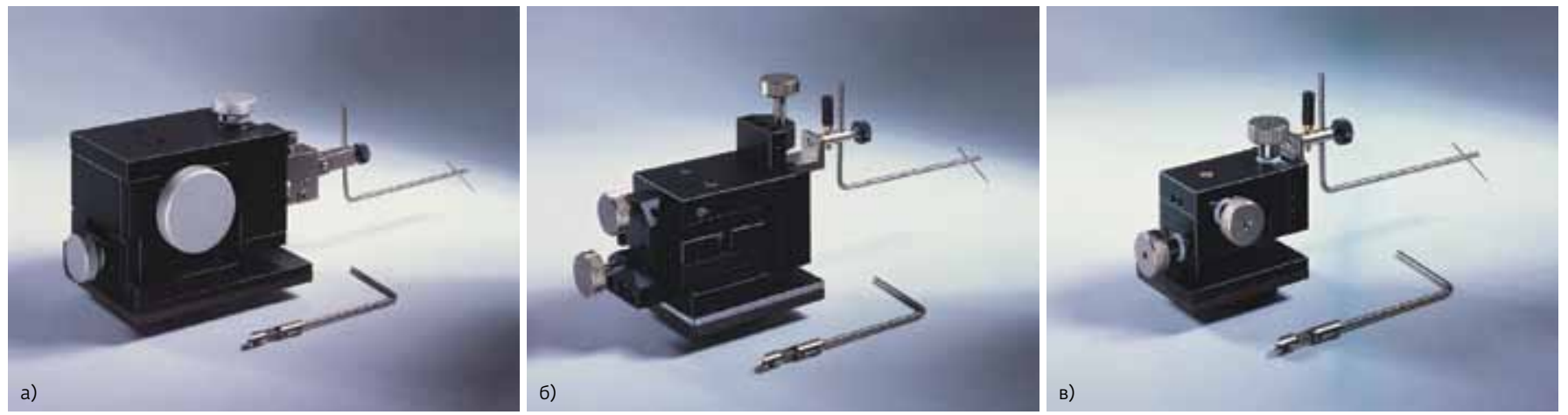

Рис.2. Микроманипуляторы компании EverBeing: а - модель EB-005 с разрешением 0,35 мкм; 6 - модель EB-050 с разрешением 0,8 мкм; в - модель ЕВ-700 с разрешением 1,7 мкм 
СВЧ-головки не выровнены или находятся на разном расстоянии относительно друг друга, результаты измерений будут различаться. Чтобы иметь возможность выполнить качественное контактирование, необходимо использовать микроманипуляторы с высоким разрешением. К примеру, микроманипуляторы производства компании EverBeing (рис.2) обеспечивают высокоточное контактирование с разрешением от 0,35 мкм (200 витков на одном дюйме резьбы). Данные устройства позволяют выполнять прецизионное линейное перемещение в трех направлениях и имеют возможность установки зондовых головок для проведения измерений на постоянном токе и СВЧ.

При проведении измерения постоянного тока малой величины требуется очень тщательно выбирать комплектующие зондовой станции, чтобы исключить влияние как внешних факторов окружающей среды, так и зондовой станции на результаты. Во-первых, необходимо учесть, что внешний фоновый шум оказывает значительное влияние на процесс измерений, а держатель пластин представляет собой большую антенну, улавливающую этот шум. Во-вторых, ток утечки обычных коаксиальных кабелей составляет десятки наноампер, что не позволяет измерять малые токи. Для снижения токов утечек используются триаксиальные кабели, содержащие дополнительный проводник (Guard-экран) с управляемым потенциалом, который поддерживается равным потенциалу сигнального проводника (рис.3). При измерении токов в фемптоамперном диапазоне, помимо всего перечисленного, необходимо полностью изолировать зондовую станцию от внешних воздействий (механических вибраций, электромагнитных помех, света).

При измерении ВФХ появляется другая особенность, обусловленная уменьшением скорости измерения за счет наличия паразитной емкости держателя пластин и влияния пьезоэлектрических эффектов, возникающих при сгибании и перемещении кабелей. Устра-

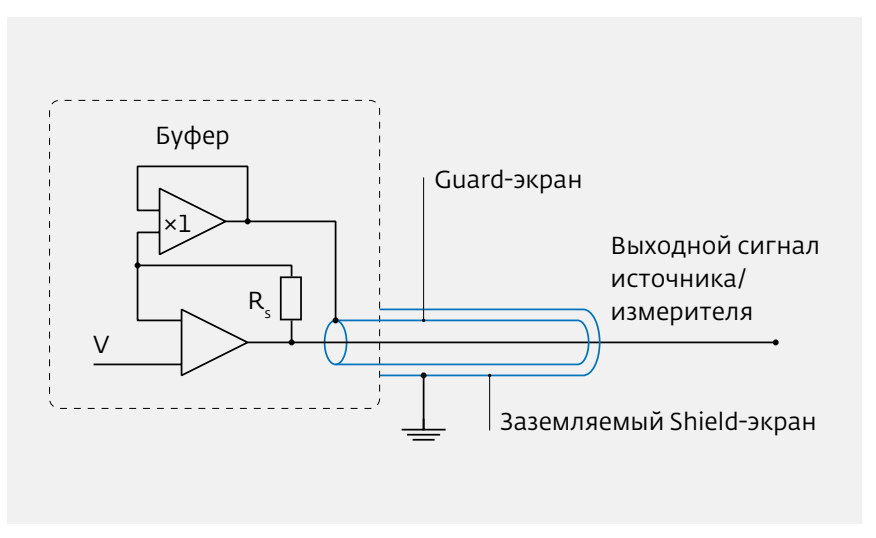

Рис.3. Упрощенная схема управления Guard-экраном нение паразитной емкости и снижение токов утечки в оборудовании компании EverBeing обеспечивается за счет специального четырехпроводного подключения держателя пластин по схеме Кельвина, которое по аналогии с триаксиальными кабелями содержит защитный Guard-экран (рис.4). Реализация такой системы подключения позволяет исключить влияние указанных негативных эффектов и увеличить скорость измерения.

Термоизмерения - еще один непростой момент при измерениях на пластине. Возникает целый ряд проблем, связанных как с самой системой терморегулирования, так и с появлением дополнительных внешних источников помех:

- система терморегулирования представляет собой электронную систему, поэтому она является источником шума;

- во время измерений при высоких температурах исследуемое устройство окисляется, поэтому могут заметно меняться замеряемые параметры;

- работа при низких температурах сопровождается выделением влаги из воздуха, ее конденсацией на зондовых головках и на образце в виде инея, что также ведет к искажению результата измерений.

Для решения описанных проблем компания EverBeing предоставляет держатели пластин с системой терморегулирования, обеспечивающей высокую точность поддержания температуры $\left(0,1^{\circ} \mathrm{C}\right)$ и малые шумы (до 10 фА). В зависимости от потребностей система может работать в диапазоне отрицательных температур как от жидкого азота, так и от охлажденного воздуха. Специальная система вентиляции устраняет из области измерения воздух, вытесняя его азотом. В результате удается решить проблему с окислением при высоких температурах и конденсацией влаги при низких.

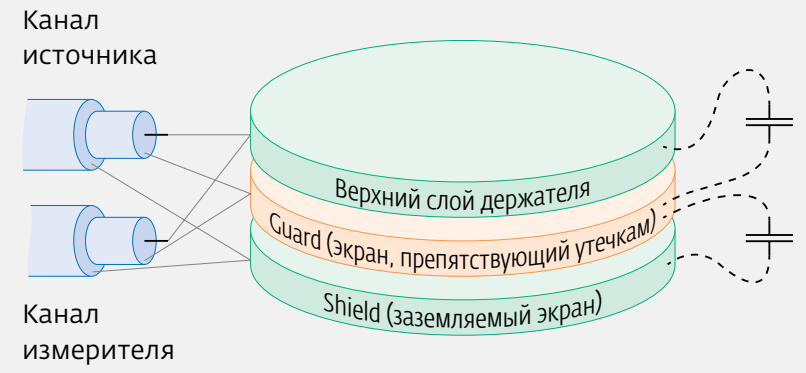

Рис.4. Четырехпроводная схема подключения держателя пластин для снижения собственной емкости и токов утечки 
При проведении зондовых измерений могут возникать и другие проблемы. Так, при организации рабочего места на конкретном участке возможен целый ряд специфических трудностей, которые не удается преодолеть с помощью стандартных средств. В таких случаях инженеры компании EverBeing могут модифицировать любое стандартное оборудование под кон- кретные нужды пользователя. Кроме того, EverBeing предлагает готовые комплексные решения, которые гарантируют токи утечки не более 10 фА и возможность проведения термоизмерений в диапазоне температур от -60 до $300^{\circ} \mathrm{C}$. Решение включает в себя непосредственно зондовую станцию, термостолик с воздушной системой регуляции нагрева, виброизоляцион-

Преимущества оборудования компании EverBeing

\begin{tabular}{|c|c|c|}
\hline Задача & Решение от EverBeing & Преимущество \\
\hline $\begin{array}{l}\text { Воспроизводимый } \\
\text { механический } \\
\text { контакт с ИУ }\end{array}$ & $\begin{array}{l}\text { Прецизионные микрома- } \\
\text { нипуляторы с разрешением } \\
\text { от } 0,35 \text { мкм }\end{array}$ & $\begin{array}{l}\text { • Высокоточное линейное перемещение по трем осям; } \\
\text { • оптимальное соотношение цена / качество; } \\
\text { • собственное производство в Тайване }\end{array}$ \\
\hline $\begin{array}{l}\text { Снижение влия- } \\
\text { ния зондовой } \\
\text { станции и внеш- } \\
\text { них воздействий } \\
\text { на результаты } \\
\text { измерений }\end{array}$ & $\begin{array}{l}\text { Подключение по четырехпро- } \\
\text { водной схеме держателя для } \\
\text { снижения паразитной емкости, } \\
\text { специальные держатели игл } \\
\text { с малыми токами утечки, экра- } \\
\text { нированные камеры, виброизо- } \\
\text { ляционные столы }\end{array}$ & $\begin{array}{l}\text { • Проведение измерений с точностью до } 10 \text { фА, сниже- } \\
\text { ние емкости держателя пластин; } \\
\text { • доработка стандартных решений под конкретные } \\
\text { нужды заказчика; } \\
\text { • исключение влияния света и вибрации }\end{array}$ \\
\hline $\begin{array}{l}\text { Проведение термо- } \\
\text { измерений }\end{array}$ & $\begin{array}{l}\text { - Системы терморегулирования } \\
\text { на основе жидкого азота или } \\
\text { охлажденного воздуха; } \\
\text { • система вентиляции для } \\
\text { работы в области высоких } \\
\text { и низких температур }\end{array}$ & $\begin{array}{l}\text { • Возможность проведения измерений в широком диа- } \\
\left.\text { пазоне температур (от -65 до } 300^{\circ} \mathrm{C}\right) \text {; } \\
\text { • устранение проблемы с окислением образца при } \\
\text { высоких температурах и с выпадением инея при } \\
\text { низких; } \\
\text { • уровень цен на 30-40\% ниже по сравнению с анало- } \\
\text { гичной продукцией, представленной другими ком- } \\
\text { паниями на российском рынке }\end{array}$ \\
\hline $\begin{array}{l}\text { Докомплектация } \\
\text { зондовой станции }\end{array}$ & $\begin{array}{l}\text { Модульная система оборудова- } \\
\text { ния, позволяющая дооснащать } \\
\text { станцию дополнительными } \\
\text { опциями }\end{array}$ & $\begin{array}{l}\text { • Возможность поэтапного оснащения зондовой стан- } \\
\text { ции; } \\
\text { • более гибкий подход к выбору оборудования; } \\
\text { • дооснащение станций сторонних производителей }\end{array}$ \\
\hline $\begin{array}{l}\text { Создание автома- } \\
\text { тизированного } \\
\text { измерительного } \\
\text { комплекса }\end{array}$ & $\begin{array}{l}\text { Специальное программное } \\
\text { обеспечение, написанное под } \\
\text { нужды заказчика }\end{array}$ & $\begin{array}{l}\text { - Создание автоматизированного измерительного ком- } \\
\text { плекса под ключ; } \\
\text { • увеличение скорости проведения измерений; } \\
\text { • вывод результатов измерений в удобном для заказ- } \\
\text { чика виде }\end{array}$ \\
\hline $\begin{array}{l}\text { Проведение крио- } \\
\text { генных или высо- } \\
\text { котемпературных } \\
\text { измерений }\end{array}$ & $\begin{array}{l}\text { Криогенные станции низкого } \\
\text { давления }\end{array}$ & $\begin{array}{l}\text { • Проведение измерений в диапазоне от -196 до } 1000 \text { C } \\
\text { при давлении 0,1 мПа; } \\
\text { • вывод органов управления положением микромани- } \\
\text { пуляторов за пределы камеры для удобства работы; } \\
\text { • легкий способ перемещения микроскопа благодаря } \\
\text { креплению на специальной раме }\end{array}$ \\
\hline $\begin{array}{l}\text { Измерение удель- } \\
\text { ного сопротивле- } \\
\text { ния материалов }\end{array}$ & $\begin{array}{l}\text { Четырехзондовые установки для } \\
\text { измерения удельного и поверх- } \\
\text { ностного сопротивления }\end{array}$ & $\begin{array}{l}\text { Измерение удельного сопротивления пластин диаме- } \\
\text { тром от } 50 \text { до } 300 \text { мм при разных температурах (150, 300, } \\
\left.400 \text { и } 500^{\circ} \mathrm{C}\right)\end{array}$ \\
\hline
\end{tabular}



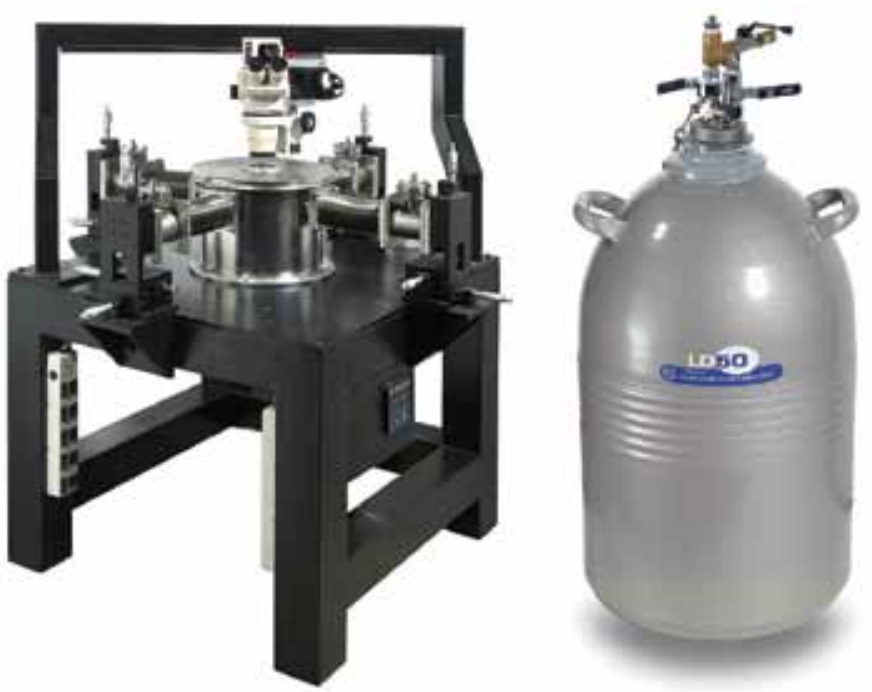

Рис.5. Криогенная зондовая станция CG-196

ный столик и экранированную камеру. Уникальность такого решения состоит в возможности его модульной комплектации и дооснащения в зависимости от условий задачи.

Для автоматизированного измерительного комплекса, состоящего из зондовой станции и измерительного оборудования, возможно написание специального программного обеспечения, которое предоставляет возможность проводить заданный набор тестов и разбраковывать кристаллы по категориям в зависимости от разброса их характеристик. Такой подход позволяет интегрировать оборудование от разных производителей в единый комплекс, что обеспечивает гибкость при выполнении измерений.

Кроме стандартного оборудования компания EverBeing предлагает решения для измерений на пластинах при криогенных температурах. Установка CG-196 (рис.5) рассчитана на работу в широком диапазоне температур - от -196 до $1000^{\circ} \mathrm{C}$ при давлении до 0,1 Па. Охлаждение происходит с помощью жидкого азота, который поступает из входящего в комплект сосуда Дьюара и контролируется посредством соответствующего клапана и давления подаваемого азота (газа). Органы управления микроманипуляторами расположены за пределами камеры, и оператор может корректировать положение игл без разгерметизации установки. Это особенно удобно при работе в области очень низких или высоких температур, так как в этом случае из-за термического расширения или сжатия материалов необходимо корректировать положение игл для обеспечения качественного контакта. Микроскоп расположен на специальной раме и может легко перемещаться, когда требуется вскрытие камеры или установка игл

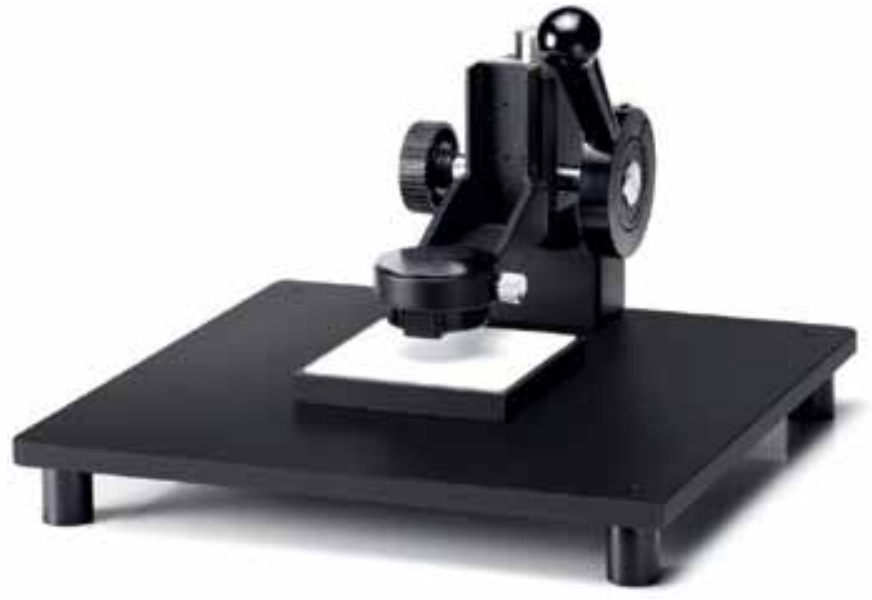

Pис.6. Установка SR-4

на контактные площадки. Собственная разработка и изготовление позволяют снизить стоимость данной установки на 30-40\% по сравнению с аналогами на российском рынке.

В технологии производства кремниевых интегральных схем и при отработке новых технологических процессов важен контроль удельного сопротивления полупроводниковых и металлических функциональных слоев. Для этих целей компания EverBeing предлагает установку SR-4 (рис.6), которая с помощью четырехзондового метода позволяет определить поверхностное и удельное сопротивление. Особенности данной установки - легкий способ контактирования с исследуемым образцом и возможность проведения измерений при разных температурах.

Таким образом, на базе оборудования EverBeing можно построить автоматизированный измерительный комплекс, удовлетворяющий современным требованиям, предъявляемым к зондовым измерениям (см. таблицу). Инженеры компаний Остек и EverBeing готовы спроектировать решение под ключ непосредственно под задачи заказчика. 